DOI: https://doi.org/10.30749/2177-8337.v23n46p175-189

\title{
POLÍTICAS PÚBLICAS DE INSERÇÃO DE MENORES INFRATORES
}

\section{PUBLIC POLICY INSERTION OF MINOR INFRARES}

\author{
Manoel Manhães Ferreira Leontino* \\ Vitor Manoel da Silva Portella**
}

\begin{abstract}
Resumo: O objetivo do presente artigo é demonstrar, e também particularizar, a ineficácia das políticas públicas vigentes de ressocialização de menores infratores no Estado do Rio de Janeiro. Ao longo do presente estudo será discutido o Estatuto da Criança e do Adolescente (ECA) e questões como a pobreza e criminalidade. As políticas socioeducativas oportunizam a reintegração do menor ao ambiente social, contudo, apesar da institucionalização de políticas públicas voltadas para o combate à violência, criminalidade e desigualdade, os programas vigentes encontram-se longe de atender de maneira específica os objetivos aos quais se destinam, apesar Doutrina da Proteção Integral.
\end{abstract}

Palavras-chave: Menor Infrator. Políticas Públicas. ECA. Ressocialização. Medidas Socioeducativas.

Abstract: The aim of this article is to demonstrate, and to particularize, the ineffectiveness of the current public policies of resocialization of juvenile offenders in the State of Rio de Janeiro. Throughout this study will be discussed the Estatuto da Criança e do Adolescente (ECA) and issues such as poverty and crime. The socioeducational policies provide opportunities for the reintegration of the minor into the social environment. However, despite the institutionalization of public policies aimed at combating violence, crime and inequality, current programs are far from specifically meeting the objectives for which they are intended, despite the Doctrine of Integral Protection.

Keywords: Minor offender. Public policy. ECA. Resocialization. Educational measures.

\footnotetext{
* Mestrando pela Universidade Augusto Motta (UNISUAM). Pós-graduado do Curso de Direito Penal pela Faculdade Internacional Signorelli. Graduado em Direito pela Universidade Augusto Motta. E-mail: manhaesferreira@yahoo.com.br

** Pós-graduado em Gestão Pública pela Faculdades Integradas de Jacarepaguá (FIJ). Graduado em Direito pela Universidade Gama Filho.
} 


\section{INTRODUÇÃO}

Os problemas que a população de uma determinada localidade apresenta devem ser entendidos e solucionados através da adoção propícia de políticas públicas, cuja elaboração, planejamento e execução fazem parte das competências do setor público. Entretanto, é possível constatar que nas mais variadas situações, as mesmas não apresentam uma sistematização para o seu planejamento e consequente execução, em virtude dos diferenciados interesses apresentados pelas partes envolvidas.

Assim sendo, a concepção de políticas públicas engloba processos decisórios e posteriores orientações, intervenção governamental e a escolha das melhores decisões; tais políticas podem ser executadas pelo ente estatal, por organizações voluntárias, sem fins lucrativos, e também, por organizações não governamentais.

A violência e a criminalidade sempre fizeram parte da vida da sociedade, entretanto, nos últimos anos foi possível observar o seu crescimento vertiginoso, o acarreta preocupações do Estado, das comunidades carentes e do próprio ambiente familiar. Na atualidade, as principais vítimas e também autores de atos ilícitos são as crianças e os adolescentes. Anteriormente, a marginalização, a desigualdade social, a exclusão, o racismo, entre outros fatores levavam a sociedade a acreditar que somente a população negra, menos favorecida economicamente eram capazes de praticar infrações. Este cenário mudou e o perfil dos infratores também, ou seja, nos dias atuais, independentemente da cor, situação econômica e financeira pessoas de todas as classes e etnias cometem infrações.

No Brasil (1988), após a promulgação da Constituição Federal (CF/88) é possível verificar os avanços referentes à legislação de uma maneira geral, inclusive no que diz respeito aos direitos dos jovens e adolescentes, assim como as relações responsáveis, as quais são devidamente compartilhadas entre a sociedade, a comunidade, o governo e a própria família.

Apesar da preocupação com a qualidade de vida do cidadão na sociedade, e também das garantias asseguradas pela $\mathrm{CF} / 88$, o adolescente continua vulnerável após cometer atos infracionais, tendo em vista a falta de acompanhamento. Ter 
princípios reconhecidos legalmente, ou seja, dignidade da pessoa humana e igualdade em várias situações não representam vida digna e produtiva, tendo em vista que não são verificadas grandes mudanças de comportamento dentro da sociedade, mantendo-se neste caso, a expressiva discriminação.

Diante das dificuldades existentes, desponta a seguinte dúvida, que será devidamente esclarecida no decorrer do trabalho: As Políticas Públicas de recuperação/ressocialização vigentes cumprem o seu papel efetivo?

\section{ECA e a CF/1988}

A Lei no 12.594/12 refere-se à inserção das políticas socioeducativas, ou seja, o governo deveria cumprir o seu papel quanto à elaboração de leis (políticas Públicas Sociais), porém nem sempre estas são consideradas eficientes, uma vez que as instituições que teriam a função de reintegrar o menor ao corpo social não cumprem as suas tarefas de maneira efetiva, o que torna necessário, e de forma bem imediata à revisão e adequação dos procedimentos e normas vigentes.

A CF/1988 e o ECA entendem que o tratamento dispensado ao menor infrator deve seguir a Doutrina da Proteção Integral, ou seja, após a prática de um delito, devem ser aplicadas as medidas socioeducativas compatíveis, cuja finalidade é educar, esclarecer sobre os perigos da criminalidade e violência, e principalmente ajudar o menor a reconhecer que toda atitude gera uma consequência, e no caso das penalidades impostas, elas devem ser aceitas e devidamente cumpridas; tal penalidade pode se a advertência, a reparação de danos, a prestação de serviço comunitário, a liberdade assistida, semiliberdade ou, até mesmo a internação, que é aplicada para infrações bem mais graves.

Posteriormente, após o cumprimento da sanção imposta, o mesmo tem o direito a reinclusão social, uma vez que este processo reafirma o acesso igualitário aos diversos espaços da vida, pois é uma das essências do desenvolvimento social. Dentre todas as medidas a liberdade assistida é a que apresenta o melhor êxito, tendo em vista o acompanhamento do adolescente dentro da realidade do seu ambiente familiar e social. 
A medida socioeducativa é ao mesmo tempo a sanção e a oportunidade de ressocialização, contendo, portanto, uma dimensão coercitiva, uma vez que o adolescente é obrigado a cumpri-la, e educativa, uma vez que seu objetivo não se reduz a punir o adolescente, mas prepará-lo para o convívio social (VOLPI, 2001, p. 66).

Normalmente, os jovens que entram em conflitos com a lei são oriundos de famílias pouco estruturadas, além de terem como exemplo, e até mesmo vivenciar, a prática de atos violentos no seu período de formação/desenvolvimento; neste contexto, a causa para o envolvimento com a criminalidade pode estar diretamente associado a não aceitação da sua condição desprivilegiada dentro da sociedade.

O ECA preconiza a garantia dos direitos fundamentais a todas as crianças e adolescentes brasileiros "[...] à liberdade ao respeito e à dignidade como pessoas humanas em processo de desenvolvimento e como sujeitos de direitos civis, humanos e sociais garantidos na Constituição e nas leis." (BRASIL, 1990, não paginado).

No mundo contemporâneo, o consumismo é um dos "elementos chave" para a existência dos mais variados tipos de problemas, e consequentemente, os menos favorecidos economicamente, nem sempre aceitam ou se contentam em apenas "olhar" determinado objeto; em muitas situações, a pobreza ou a falta de recurso financeiro se torna um agravante para que os indivíduos venham a roubar, isto é, na concepção do pensamento do menor, este irá adquirir aquilo que a sociedade apresenta como uma "novidade" a qualquer preço, mesmo que tenha que praticas atos ilícitos.

Anteriormente, somente os jovens negros e "pobres" eram acusados e presos, em virtude ao aliciamento ao tráfico de drogas, armas, assédio sexual ou crimes de internet. Este cenário mudou, constata-se que o tráfico, o consumo e o próprio comércio virtual, ou seja, artigos de vestuário, tecnológico (ipods, telefone celular, palm-tops) tornaram-se uma prática também dos jovens brancos e bem mais afortunados economicamente, pois se comprova uma modificação dos perfis.

$\mathrm{Na}$ atualidade, não existe um comprometimento para a formação dos indivíduos que irão compor o país futuramente, ou seja, as crianças e os adolescentes; diante de tal fato, tornou-se muito comum os pais, familiares ou 
responsáveis legais procurar ajuda na Vara da Infância e Juventude, antigo Juizado de Menores, a partir do momento em que tomam consciência de que não possuem controle sobre a educação dos próprios filhos. A "violência" é um reflexo das humilhações impostas aos seres humanos, ou seja, são detectadas no ambiente de trabalho, no ambiente doméstico e na própria rotina social.

No Brasil, com o crescente quadro de abandono de crianças e diante da despreocupação da sociedade em acolher esta infância desvalida, estes infortunados passaram a ser estigmatizados de menores, num sentido pejorativo, que recebe a conotação de criminosos e infratores. Naquele momento, mais especificamente em 1922, passou a funcionar, no Rio de janeiro, o primeiro estabelecimento público de atendimento a menor do Distrito Federal. (CUCCI, 2009, p. 194).

Acabou se tornando elementar rever as práticas voltadas para a formação de crianças e adolescentes, no que diz respeito à aplicação de leis, que possam atuar diretamente na solução dos problemas da criminalidade infanto-juvenil, assim como, oportunizar meios para que seja possível estabelecer uma vida em sociedade com menores índices de violência, principalmente junto à população que apresenta maiores riscos. (MATOS, 2006).

\section{AS PRÁTICAS SOCIOEDUCATIVAS}

As práticas socioeducativas destinadas aos jovens, em especial aos de baixa renda, não oferecem condições muito favoráveis para a transição do indivíduo para a fase adulta, isto é, o futuro apresenta poucas chances de melhoria na vida. O tempo disponível destes indivíduos, não deve ser preenchido como ações meramente "presentistas", as quais são oferecidas pelas instituições tradicionais de socialização, quer dizer, formação apenas de caráter compulsório, institucional e complementar. Os jovens necessitam de uma ampliação total dos seus níveis de conhecimento, cujo objetivo é evidenciar melhorias no momento atual, e principalmente, estas devem alicerçar o futuro, ou seja, período da fase adulta. (SPÓSITO, 2009).

A pobreza, principalmente urbana, caracterizada pela precariedade de condições de vida, pela ausência ou limitação de recursos públicos de infraestrutura e serviços, e pelo enfraquecimento das solidariedades 
entre vizinhos, transforma-se na principal causa a ser combatida, propondo-se como intervenção a promoção social do adolescente e sua família. (LIANA, 2011, p. 5).

Apesar da sobriedade, a sociedade brasileira apresentou significativos progressos no que tange à democracia, bem como no aprovisionamento de bens coletivos, principalmente os que se encontram relacionados à educação, à saúde e ao trabalho; entretanto, apesar dos avanços na esfera democrática, constata-se uma severa decomposição do setor público quanto ao controle dos níveis do crescimento da criminalidade e violência. (SAPORI, 2007).

Violência e criminalidade são elementos cotidianos no meio urbano, apesar de também ocorrer no meio rural; negros e pobres são normalmente considerados os autores e vítimas de tais práticas, apesar da comprovação de existência também dentro da população branca e com melhores condições econômicas e financeiras.

A deterioração da ordem pública nos últimos anos pode ser constatada pela faixa etária dos jovens, uma vez que apresentam idades entre 15 e 29 anos. Os processos de exclusão e tração dos infratores foram fortemente disseminados através dos meios de comunicação em massa, pela compreensão de atitudes individualistas, pelos modelos culturais evidenciados pela classe média, e pelo próprio consumismo. O crescimento da violência junto à população menos favorecida economicamente é decorrente da contradição e simultaneidade existente entre o "mundo dos ricos" e o "mundo dos pobres", além das desigualdades sociais.

O Poder Judiciário tem a função de legitimador da democracia e dos direitos. Sua função estende-se a respaldar ou rejeitar práticas governamentais que possam desencadear 0 aumento de desigualdades e tantos males sociais, pois quanto maior o hiato se fizer presente entre o sistema normativo e a realidade social, mas se obterá a falta de efetividade e a total deslegitimação da ordem jurídica. (BONAVIDES, 2018, p. 63).

Através das políticas socioeducativas, a legislação brasileira oferece amparo às crianças e adolescentes, que acabam por se envolverem em conflitos legais, cuja finalidade é proporcionar a reintegração dos mesmos no meio social. Entretanto, para que seja estabelecido um ambiente apropriado e de "convivência pacífica", são praticadas determinadas ações institucionais e jurídicas um tanto quanto desumanas 
e arbitrárias, tendo em vista, as tensões apresentadas pelos adolescentes, ou seja, os padrões de violência já criaram raízes profundas dentro do indivíduo). (MATOS, 2006).

Historicamente, é totalmente oportuno avaliar as condições de vida apresentadas pelo menor, ou seja, os aspectos culturais, familiares e econômicos, tendo em vista que:

Crime não é visto como uma patologia (uma doença), mas como uma relação multicausal complexa com raízes na própria sociedade [...] com ênfase nas condições sociais e estruturais da sociedade capitalista que propicia o surgimento da delinquência [...] as condições culturais também propiciam uma ambiente mais ou menos favorável ao delito e à reincidência, pois marcam um lugar para o sujeito na construção de sua história e das mudanças de sua trajetória. (FALEIROS, 2004, p. 90-91).

O Estado oportuniza as seguintes garantias ao direito social relativo aos menores, através da promulgação da Lei no 12.594/12 (Sistema Nacional de Atendimento Socioeducativo): medidas socioeducativas que não privam a liberdade do indivíduo, tais como: a prestação de serviços comunitários, a liberdade com o devido acompanhamento, a repreensão e a retração aos danos cometidos; e, medidas que privam a liberdade do ser, as quais englobam a internação, e também, os processos de semiliberdade.

Art. 227. É dever da família, da sociedade e do Estado assegurar à criança, ao adolescente e ao jovem, com absoluta prioridade, o direito à vida, à saúde, à alimentação, à educação, ao lazer, à profissionalização, à cultura, à dignidade, ao respeito, à liberdade e à convivência familiar e comunitária, além de colocá-los a salvo de toda forma de negligência, discriminação, exploração, violência, crueldade e opressão. (BRASIL, 1990, não paginado).

De acordo com o art. 112 do ECA (BRASIL, 1990) será admitido o menor que praticar atos infracionais considerados "leves", e desde que o menor seja primário, ou, que as infrações ocorram de maneira ocasional. A advertência é um aviso verbalizado, porém, será reduzida a termo e assinada; a referida ação consiste em avisar, informar de maneira imediata o menor, assim como aos seus responsáveis e familiares sobre o risco de envolvimento em atos infracionários. 
O art. 116 delibera sobre as obrigações de reparação de danos ao patrimônio; dependendo do entendimento das autoridades competentes, o menor deverá repor o objetivo danificado, de maneira a compensar os prejuízos causados à vítima. Este é um procedimento obrigatório, embora a finalidade seja "educativa", isto é, uma tentativa para que o menor reconheça os seus erros e venha a reparálos. Embora válida, nos dias atuais é pouco aplicada em virtude da carência financeira dos menores infratores, e também por ocasionar ônus aos pais ou responsáveis.

[...] os direitos fundamentais são multifuncionais, um mesmo direito fundamental pode tanto ter função defensiva como prestacional. E é esse caráter multifuncional que ajusta a edificação de uma sociedade inclusiva, [...] menos excludente com vistas a proporcionar a concessão de direitos aptos a transformar a situação de abandono que parcela qualitativamente significativa da população está inserida. (LIMA, 2011, p. 268).

O art. 117 disciplina sobre as aplicações de serviços comunitários, os quais normalmente são gratuitos, além se servirem ao interesse geral e para o próprio bem-estar da coletividade, tais como: desempenho de atividades em ambientes hospitalares, escolares, entidades assistenciais e estabelecimentos semelhantes, programas comunitários ou governamentais; tais práticas não poderão ser superiores ao período de seis meses. A prestação de serviço comunitário acaba promovendo o envolvimento do adolescente com o seu núcleo familiar e com a comunidade, tendo em vista que, as tarefas são atribuídas mediante as aptidões individuais, além de não ser admitida nenhuma situação que venha a ocasionar vexame ou constrangimento.

De sorte que, é difícil para o legislador ou para o executivo garantir que uma norma de lei vá ser aplicada conforme foi engendrada e homologada. Há uma autonomia possível para cada agente de implementação proceder de acordo com suas referências. Igualmente existem outros fatores ou variáveis independentes da vontade do legislador, como as condições contextuais e os fatores subjetivos a cada agente envolvido. (OLIVEIRA, 2012, p. 28-29).

O art. 119 do ECA dispõe sobre a liberdade assistida; esta apresenta os melhores êxitos, uma vez que existe o acompanhamento do adolescente dentro da sua realidade social e familiar, ao serem estabelecidos valores e reflexões sobre as 
práticas de atos ilícitos. A liberdade assistida é aplicada aos menores que cometem infrações "menos graves", ou como medida inicial, e também, nas situações de afastamento das medidas de semiliberdade e internação nos seus processos conclusivos.

As medidas privativas de liberdade devem respeitar os princípios dos direitos humanos, pelo menos de forma teórica, apesar da constatação de violações na aplicação e execução das medidas socioeducativas. O Brasil é marcado por traços de segregação e desrespeito aos direitos humanos. Observa-se que, por inúmeras vezes, os dirigentes optam pelo processo de internação em locais desumanos, ao invés de tentar outros tipos de medidas.

O art. 120 disciplina sobre o regime de semiliberdade, ou seja, medida alternativa para que o menor não venha a ser totalmente institucionalizado; neste caso, o infrator terá restrições quanto à sua liberdade; tal processo pode ser aplicado na fase de internação ou reingresso social, no período diurno para a realização de trabalhos externos, e no período noturno, ou seja, o menor deverá ser recolhido de volta à entidade, e contará com o apoio de orientadores e técnicos sociais. 0 autoritarismo se faz presente nesta medida, ao ser possível evidenciar o afastamento do adolescente com a sociedade e núcleo familiar, apesar do mesmo não ser privado do seu direito de ir e vir.

O art. 121 disciplina sobre a medida socioeducativa com o maior grau de severidade, ou seja, a internação, apesar dos seus aspectos pedagógicos e educativos. Tal restrição não pode ou deve privar o menor dos seus direitos fundamentais, isto é, deve apenas limitar o seu trânsito.

[...] as medidas socioeducativas [...] são aplicadas com uma finalidade educativa e de inibição da reincidência; ou seja, os métodos, para sua aplicação, devem incluir a assistência de profissionais ligados à área social, pedagógica, psicológica, psiquiátrica e outras, possibilitando sua integração na família e na comunidade8 consolidando, assim, a garantia de todos os direitos constitucionalmente assegurados. (LIBERATTI, 2002, p. 128).

O ECA considera como menor infrator, o indivíduo com idade entre 12 e 18 anos incompletos, devendo este receber um tipo de tratamento consentâneo com o 
seu âmbito sócio-familiar, e principalmente, quanto à sua fase de desenvolvimento. Apesar da promulgação da Lei no 8.069/90, verifica-se que a legislação brasileira passou por processos de transformações; entretanto, em determinadas situações, as instituições e as utopias sociais mantém as mesmas, o que tende a propiciar a reincidência das infrações e consequente aumento da criminalidade.

A ressocialização é um problema que muito inquieta a sociedade, em virtude da ausência de um comprometimento político efetivo com a população vulnerável, assim como a crise econômica e suas oscilações, pois os intentos políticos representam apenas os interesses da classe dominante.

As políticas sociais do tipo setoriais é um terreno novo no campo da Ciência Política, a qual enfoca, sobretudo o aspecto técnico. Acresce ainda que o caráter apolítico do enfoque, até agora dominante, tem influenciado a orientação com que se tem encarado a produção teórica a respeito, basicamente centrada na análise evolutiva e comparativa dos diferentes modelos institucionais e programáticos das políticas da juventude e a vinculação das políticas sociais da juventude com os processos de reforma administrativa. (ABAD, 2003, p. 16-17).

No Brasil, anteriormente o atendimento ao menor representava um "auxílio à pobreza", o qual passou da caridade à filantropia, até que se tornou um problema de ordem e ações públicas, pois se acreditava que ser "pobre" era uma condição religiosa ou social, ou seja, um meio para se alcançar a salvação. Posteriormente, a sociedade industrial começou a intervir, cujo objetivo era instruir e capacitar os menores para o mercado de trabalho. "Aos poucos se altera a visão caritativa, essencialmente religiosa e moral na busca de salvar a alma, em troca de salvar os corpos, através da filantropia", segundo Colombo (2006, p. 35).

Pode se afirmar que a nova condição juvenil se constrói sobre o pano de fundo da crise das instituições tradicionalmente consagradas à transmissão de uma cultura hegemônica, cujo prestígio tem se debilitado pelo não cumprimento de suas promessas e pela perda de sua eficácia simbólica como ordenadoras da sociedade. (ABAD, 2003, p. 26).

Todos os indivíduos, inclusive os adolescentes possuem direitos assegurados por lei, no que diz respeito à igualdade de tratamento, ou seja, não é admitido nenhum tipo de diferenciação ou discriminação, cujo objetivo é respeita à vida, à 
segurança, à liberdade, à igualdade, bem como a própria história de vida do indivíduo. Tais elementos demonstram a existência de uma sociedade totalmente democrática, na qual são aceitas as adversidades existentes, incluindo os adolescentes que cometem atos ilícitos. Entretanto, verifica-se uma significativa desconsideração com estes indivíduos, pois os mesmos não são incluídos na pauta prioritária da esfera governamental.

A sociedade cobra medidas repressivas, porém é totalmente omissa na luta por melhoramento das qualidades de atendimento para estes jovens. As instituições, que teriam a função de ressocializar, apenas estigmatizam estes adolescentes, o que pode ser comprovado pelo insucesso das medidas socioeducativas, ou seja, após o cumprimento da penalidade devida, este jovem continuará desamparado e com poucas chances de uma reinclusão verdadeira na sociedade, ou seja, estes continuarão a serem rotulados como um "perigo" para a população.

$\mathrm{Na}$ atualidade, as verdadeiras preocupações da sociedade deveriam estar destinadas à efetiva prática do ECA, pois é inadmissível que após vinte anos da sua promulgação, a realidade continue apenas "teórica", ou seja, pouca prática daquilo que esta devidamente estabelecido por lei.

No mundo contemporâneo, a violência e a criminalidade independem de raça, cor, sexo ou condição social; anteriormente, acreditava-se que apenas os "negros e pobres" um dia se tornariam "infratores"; este perfil e cenário foram modificados ao longo do tempo, em virtude dos mais variados fatores.

Tornou-se imperativo aceitar que "adolescentes infratores" devem ser tratados como um problema prioritário, com a independência da existência de relações de autoritarismo, relativas ao poder e valor econômico, da baixa capacidade política, ou atém mesmo, da precariedade das instituições, visto que, toda ação irá proporcionar uma reação, e que as omissões também geram consequências bastante significativas, o que neste caso fica evidenciado pelo aumento da violência e o número abundante de atos infracionais.

O Estado deve cumprir as obrigações e responsabilidades, mesmo que venha a desagradar os interesses de determinadas camadas sociais, devendo respeitar sempre o interesse público; assim sendo, a família e a sociedade devem oportunizar meios para o desenvolvimento social e político da nação, cuja finalidade é adequar 
determinadas ações para o atendimento das necessidades dos indivíduos mais vulneráveis.

O adolescente, ao ser conceituado como um ser dotado de direito, que detém certas prioridades, que é uma pessoa em desenvolvimento, acaba perdendo a sua verdadeira essência, isto é, este não mais será reconhecido como uma "vítima" da sociedade que o excluiu, e sim, como o agente "agressor". Após ser identificado como "infrator", este passará a arcar com as suas responsabilidades e de maneira definitiva, diante de tais fatos, tudo perderá a relevância, como por exemplo, o seu sofrimento, seus prazeres, discursos, origens, as causas que o motivaram para a prática de delitos, ou seja, tudo passará ser banalizado.

A sociedade levou muitos anos para ultrapassar o sistema político repressor e autoritário, porém, tais elementos ainda fazem parte do cotidiano da sociedade, tendo em vista a criação de "profundas raízes", visto que, "muito" foi realmente estabelecido em lei, porém, pouco divulgado e, normalmente, assumiu um caráter apenas transitório.

O Poder Público conjuntamente com a sociedade deveria reduzir o estado de retificação social, nos quais se encontram os menores infratores; entretanto, a inexistência de uma vontade política acarreta o sustento da miséria, e consequentemente, o aumento da criminalidade.

A criminalidade não é oriunda da negação do direito de proteção integral da criança e do adolescente, mas, é um dos fatores que desencadeia os atos criminais e violentos, em virtude ausência de medidas econômicas que possam devidamente inserir os que são rotulados de "marginais"; diante de tais fatos, verifica-se que não existe uma unanimidade quanto aos processos de inclusão, tendo em vista a existência de algumas máculas, para que seja possível reconhecer as diferenças, e também as relacionadas à viabilidade das medidas socioeducativas. Neste contexto, evidencia-se que jovem infrator não é o único a ser discriminado, ou seja, a família também sofre os efeitos desta condenação. 


\section{CONSIDERAÇÕES FINAIS}

Após uma extensa leitura, conclui-se que os questionamentos sobre as origens e repercussões dos crimes cometidos por menores datam desde o tempo do Brasil Colônia. A proposta apresentada pelo ECA significou o rompimento dos modelos até então praticados no país, o qual, infelizmente, se comprovou improfícuo em relação às suas expectativas, principalmente o que está diretamente relacionado à ressocializaação do jovem infrator. A composição do ECA faz parte da legislação mais avançada, porém, as medidas socioeducativas ainda possuem conotações de "pena", ou seja, não podem ser evidenciadas medidas de regeneração ou educação, o que tende a propiciar a revolta destes infratores, além de serem tendenciosas para o aumento da criminalidade.

Após a promulgação do ECA, a expressão "menor" foi substituída pelo termo "criança e adolescente", assim como "infração penal" recebeu a denominação de "ato infracional", no qual está incluída a contravenção e o próprio crime, e o "Juiz" deixou de ser o único que atua perante as práticas de atos infracionais, ou seja, na atualidade, o "Conselho Tutelar" tornou-se a nova autoridade administrativa.

Contudo, apesar das medidas alvitradas pelo ECA, a maioria dos problemas relacionados aos adolescentes infratores continuam sem solução, em virtude da realidade estrutural social e conjuntural brasileira, a qual, por sua vez imputa severos limites para a sua aplicação.

Nos dias atuais, um contingente populacional expressivo sofre com o processo de exclusão social, ou seja, não existem grandes possibilidades e expectativas para uma suposta ascensão social, assim como a automanutenção dentro da sociedade capitalista. As famílias marginalizadas acabam permitindo a saída dos seus filhos, os quais irão buscar por trabalho ou, até mesmo, a sua institucionalização, uma vez que não possuem estrutura ou recursos financeiros para a manutenção dos mesmos. Paralelamente aos fatores econômicos, outra questão de suma importância é a desagregação familiar, ou mais grave ainda, a ausência total dos familiares quando o infrator é institucionalizado. 
Assim, devemos entender que nos momentos atuais, as políticas públicas sociais e as medidas socioeducativas devem ser reelaboradas, ou seja, não devem apresentar traços de "punição", a começar pela parte estrutural das instituições, que deve ser remodelada, já que se pretende descartar a ideia de reformatório, internato, tão comum aos tempos remotos, o acompanhamento e ressocialização devem incluir os familiares e/ou responsáveis, além do menor, é preciso, principalmente, mudar a "visão" da sociedade em relação aos "infratores".

\section{REFERÊNCIAS}

ABAD, M. Crítica política das políticas de juventude. In: FREITAS, Maria Virginia de; PAPA, Fernanda de Carvalho (org.). Políticas públicas juventude em pauta. São Paulo: Cortez, 2003. p. 13-32.

BONAVIDES, P. Curso de direito constitucional. 33. ed. São Paulo: Malheiros, 2018.

COLOMBO, I. M. Adolescência infratora paranaense: história, perfil eprática discursiva. 2006. Tese (Doutorado em História) - Universidade de Brasília, Brasília, 2006.

BRASIL. Constituição da República Federativa Brasil. Brasília, DF: Congresso Nacional, 1988.

. Lei no 8.069, de 13 de julho de 1990. Dispõe sobre o Estatuto da Criança e do Adolescente e dá outras providências. Brasília, DF: Presidência da República, 1990. Disponível em: http://www.planalto.gov.br/ccivil_03/leis//8069.htm. Acesso em: 26 nov. 2018.

CUCCI, G. P. A proteção integral da criança e do adolescente como meio adequado de inclusão social. In: SIQUEIRA, Dirceu pereira; PICCIRILLO, Miguel Belinati (coord.). Inclusão social e direitos fundamentais. Birigui, SP: Boreal Editora, 2009. p. 193-209.

FALEIROS, V. P. Impunidade e inimputabilidade. Serviço Social \& Sociedade, [S.I.], ano XXIV, n. 77, 2004.

LIANA, P. Liberdade assistida: punição e cidadania na cidade de São Paulo. 2011. Tese (Doutorado em Sociologia) - Departamento de Sociologia, Faculdade de Filosofia, Letras e Ciências Humanas, Universidade de São Paulo, São Paulo, 2011. 
LIBERATTI, W. D. Adolescente e o ato infracional. São Paulo: Juarez de Oliveira, 2002.

LIMA, J. N. A cidadania social por meio de reconhecimento do direito fundamental à inclusão social. In: SIQUEIRA, Dirceu Pereira; BRITO ALVES, Fernando (org.).

Políticas públicas da previsibilidade a obrigatoriedade: uma análise sob o prisma do Estado social de direitos. Birigui, SP: Boreal Editora, 2011. p. 258-801.

MATOS, R. N. Crime e castigo: reflexões sensíveis sobre adolescentes privados de liberdade em Uberlândia. 2006. Dissertação (Mestrado em História) - Instituto de História, Universidade Federal de Uberlândia, Uberlândia, 2006.

OLIVEIRA, I. de L. M. Avaliação de Políticas Públicas de Recuperação de Aprendizagem em Alfabetização na visão de quem as implementa. 2012. Tese (Doutorado em Serviço Social) - Faculdade de Ciências Humanas e Sociais, Universidade Estadual Paulista Júlio de Mesquita Filho, Franca, 2012.

SAPORI, L. F. Política de segurança pública em Minas Gerais. In: SAPORI, L. F. Segurança pública no Brasil: desafios e perspectivas. Rio de Janeiro: FGV, 2007. p. 137-153.

SPÓSITO, M. P. O estado da arte sobre juventude na pós-graduação brasileira: educação, ciências sociais e serviço social (1999-2006). Belo Horizonte: Argvmentvm, 2009.

VOLPI, Mário. Sem liberdade, sem direitos: a privação de liberdade na percepção do adolescente. São Paulo: Cortez, 2001.

Recebido em 12/11/2019.

Aceito em 22/11/2019. 